\title{
There's More to Young Adult Unemployment Than Mental Health: What Else to Look For
}

The unemployment rate of young adults living with serious mental health conditions (SMHCs) is appallingly high when compared to young adults with other disabilities and even worse compared to young adults without disabilities. Approximately $91 \%$ of young adults with SMHCs are employed at some time since high school, while only $49.6 \%$ were employed 8 years after high school, a rate that is significantly lower than that of the general population. ${ }^{1}$ Traditionally employment research has focused on only mental health conditions related to employment, but there is more to it.

\section{OTHER BARRIERS}

People living with a mental health condition are a varied population with diverse backgrounds. ${ }^{2}$ There are some obvious barriers for these individuals when it comes to employment, such as the length and severity of the psychiatric disability, lack of access to mental health treatment, educational opportunities, lack of work experience, as well as perceived prejudice and discrimination. However, when it comes to employment specifically among young adults with SMHCs, recent research shows that these barriers are not the only factors at play. Sociodemographic factors such as gender, race, level of education, place of residence, and social capital are also critical influences in determining employment outcomes. Taking into account not only mental health determinants, but also indicators of social and demographic inequalities, is an example of intersectional research.

Intersectional research considers all aspects of one's identity and social status as key acting forces. In order to improve vocational employment services for young adults living with SMHCs, we must take into account all aspects that can impact employment readiness and employability. A broader way of looking at unemployment among young adults affected by mental health conditions is needed that examines the following sociodemographic and social factors: race and gender, level of education, place of residence, and whether a young adult is actively looking for work.

\section{RACE AND GENDER}

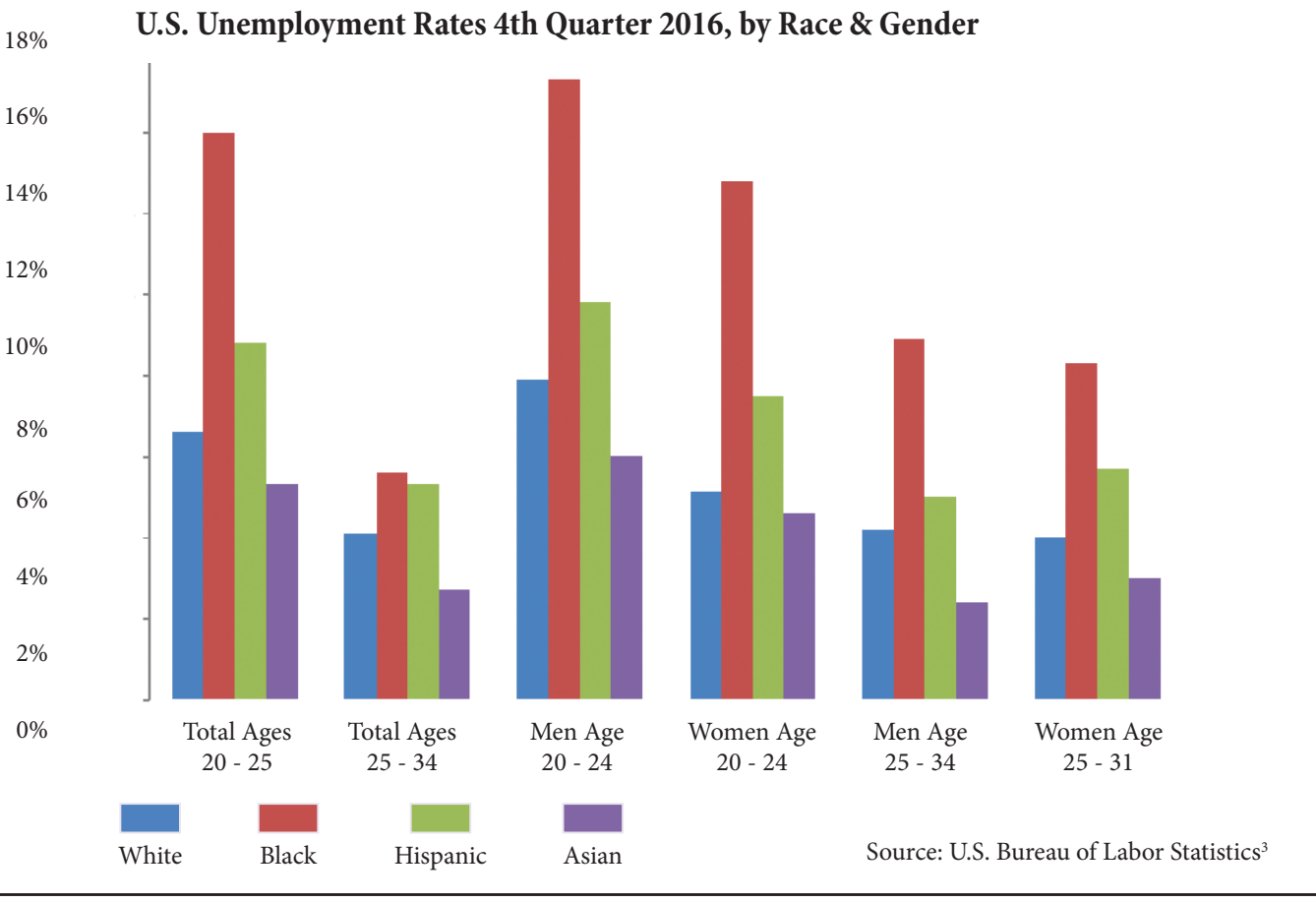


As pictured in the above graph, U.S. employment differences based on race are large overall and are even larger for young males. The Bureau of Labor Statistics has found that being a Black or Hispanic male significantly reduces the probability of employment. These data are confirmed from the National Longitudinal Survey of Youth (NLSY97), indicating that across all ages, White youth are more likely to be employed than their Black or Hispanic counterparts. ${ }^{4}$ Black males between the ages of 20 and 24 constitute the category with the highest rate of unemployment, closely followed by their Hispanic peers. ${ }^{4}$

Not having a job as a young adult also has later repercussions. Research shows that racial gaps in employment that are present in the early teen years seem to continue into adulthood and, that this prevalence is again higher among Black and Hispanic young adults compared to White or Asian young adults.

\section{EDUCATION}

Education is another critical factor in a young adult's employability. Statistics show that individuals with a higher level of education have much higher chances to be employed at a higher income. ${ }^{5}$

Looking closely at who enrolls in advanced/postsecondary education, there are striking gaps of social inequality that compound inequalities due to disability. ${ }^{6}$ For example in 2015 only $16.7 \%$ of students with a disability completed college or more, while $34.9 \%$ of students without a disability completed college or more. ${ }^{7}$ Eighty-one percent of 18 to 24 year old young adults from families with high income levels are enrolled in postsecondary education compared to only $45 \%$ of their peers coming from families with low income levels. ${ }^{6}$ Similar trends exist when it comes to race as indicated in the graph below: the percentage of Hispanic or Black young adults who completed an advanced degree is almost five times lower, compared to Asians who are higher in the rank.

These data demonstrate that education - a main predictor of employability - should be considered when it comes to developing interventions to improve young adult employability.

\section{PLACE OF RESIDENCE}

A number of studies have found that where you live-and especially the immediate neighborhood - affects the proximity to jobs and whether a young adult begins working or not. ${ }^{8}$ Living in a poor neighborhood is linked to a variety of negative conditions such as higher crime rates, failing schools, and fewer job opportunities, especially job opportunities that can lead to fulfilling careers. ${ }^{9}$ Neighborhoods with concentrated poverty are consistently cut off from social networks that help people find jobs and advance their careers. Factors such as racial and geographical discrimination (e.g., when employers don't hire people from a specific area) makes access to employment even more difficult. ${ }^{10}$

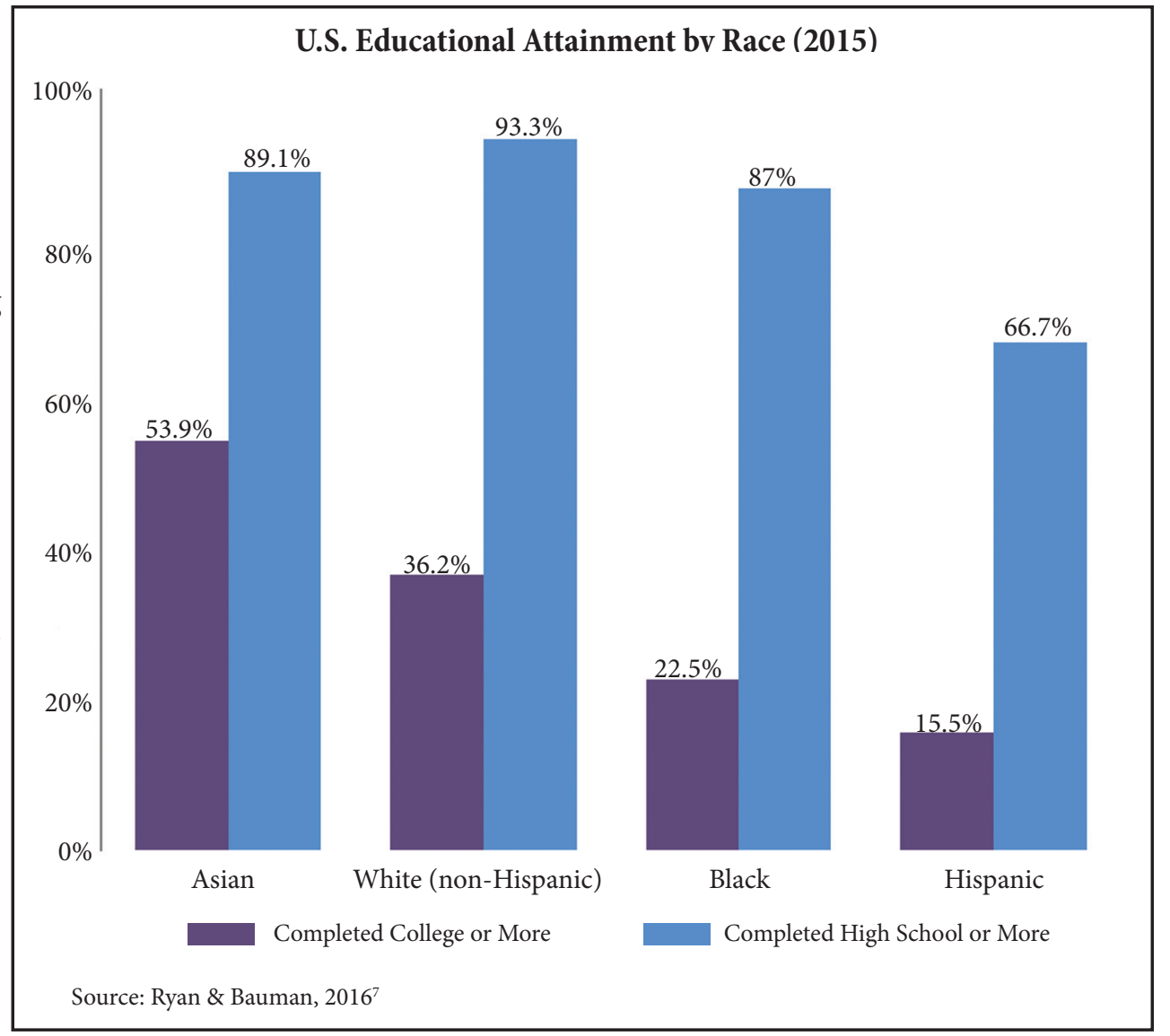


Differences between employment opportunities and trends in urban and rural locations must be considered. Notably, rural areas have higher poverty rates than urban areas, lower levels of educational attainment, and still have not reached prerecession levels of employment. ${ }^{11}$ All of these factors taken together create a vicious circle of poor quality education, fewer career opportunities, and a resulting lack of economic mobility. ${ }^{10}$

\section{LOOKING FOR A JOB} Labor force participation rate is a measure that indicates the level of interest people have in working. It includes people who are employed or unemployed as long as they are considered to be looking for work. According to recent data, today's young adult Americans face the worst employment prospects since World War II. ${ }^{12}$ The biggest drop among age groups in looking for a job has been among young adults ages 16-34. In $199251.3 \%$ of young adults between 16-19 years old were looking for a job, but in 2016 that rate had dropped to $32 \% .^{13}$ There has also been a decrease in

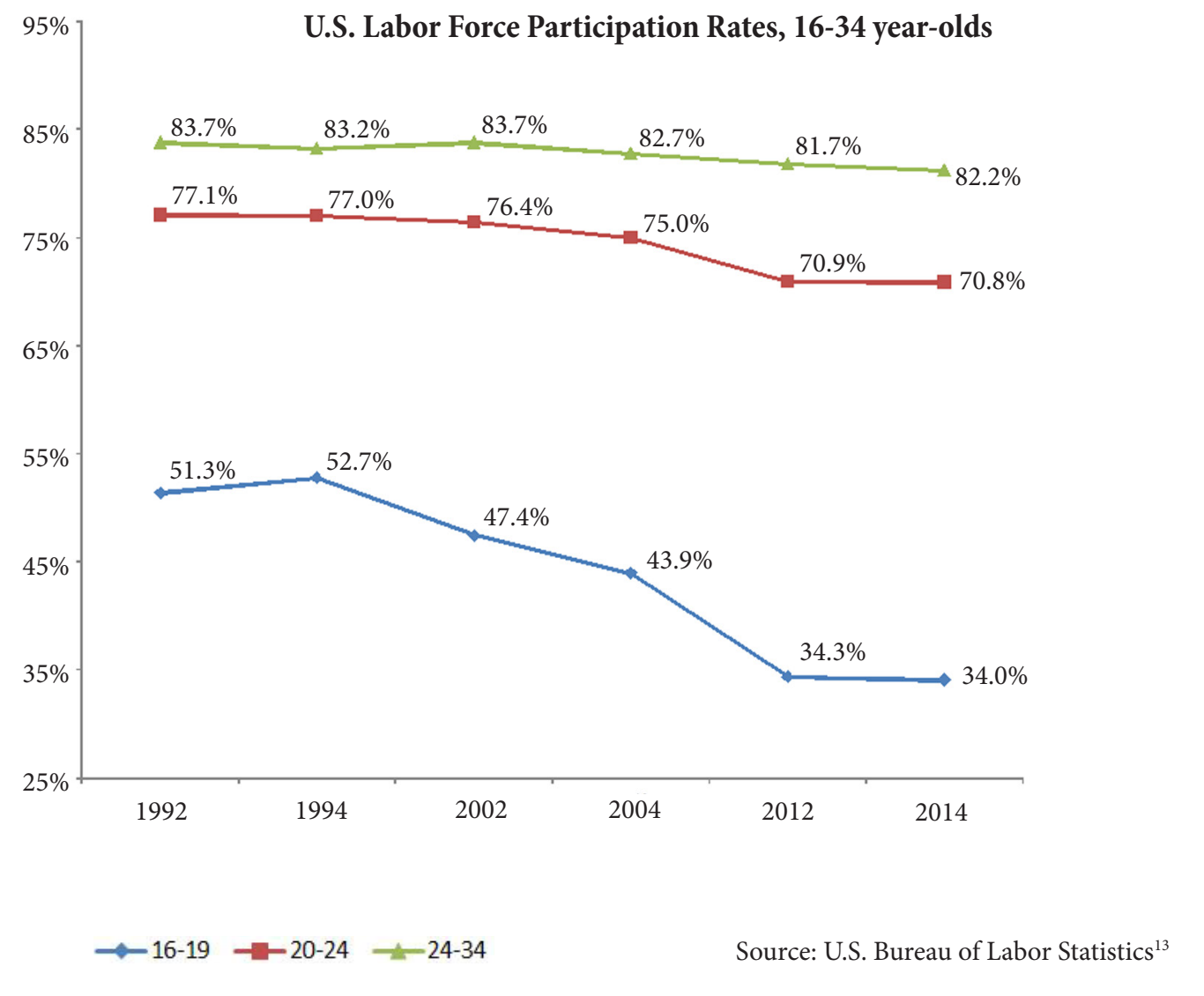
labor force participation for 20-24 year-olds. In 1992, 77.1\% of 20-24 year-olds were looking for a job, while in 2016 only $69.9 \%$ were looking for work. The drastic decrease in young adult interest in looking for employment may likely impact their ability to find work in later adulthood, regardless of also having a serious mental health condition.

\section{CONCLUSION}

The high unemployment among young adults with SMHCs should not only be attributed to their mental health conditions. Such a reductive approach ignores the fact that these mental health factors also interact with socio-demographic factors that also influence employment outcomes. Future mental health services research should take an intersectional approach - where, in addition to looking at mental health condition factors, other indicators of social and demographic inequalities are also taken into account. We can only move towards closing inequality gaps and developing effective interventions by objectively evaluating all of these factors that affect employment among young adults with serious mental health conditions. 


\section{REFERENCES}

1. Wagner, M., \& Newman, L. (2012). Longitudinal transition outcomes of youth with emotional disturbances. Psychiatric Rehabilitation Journal, 35(3), 199.

2. NAMI, the National Alliance on Mental Illness. (2014). Road to Recovery: Employment and Mental Illness. Retrieved from: https://www.nami.org/work

3. U.S. Bureau of Labor Statistics. Labor force statistics from the current population: E-16. Unemployment Rates by Age, Sex, Race, and Hispanic or Latino Ethnicity, Fourth Quarter 2016 [Data Set]. Retrieved from https://www.bls.gov/web/ empsit/cpsee_e16.htm

4. Bureau of Labor Statistics, U.S. Department of Labor. (2015). National Longitudinal Survey of Youth 1997 cohort, $1997-$ 2013 (rounds 1-16). Produced by the National Opinion Research Center, the University of Chicago and distributed by the Center for Human Resource Research, The Ohio State University. Columbus, $\mathrm{OH}$.

5. United States Department of Labor. (2010). Employment projections: Education pays in higher earnings and lower unemployment rates. (Bureau of Labor Statistics).U.S. Government Printing Office. Retrieved from http://www.bls.gov/ emp/ep_chart_001.htm

6. The Pell Institute. (2015). Indicators of Higher Education Equity in the United States - 45 Year Trend Report. Retrieved from http://www.pellinstitute.org/downloads/publications-Indicators_of_Higher_Education_Equity_in_the_US_45_ Year_Trend_Report.pdf

7. Ryan, C. L., \& Bauman, K. (2016). Educational attainment in the United States: 2015. Current Population Reports, 20. Retrieved from https://www.census.gov/content/dam/Census/library/publications/2016/demo/p20-578.pdf

8. Gardecki, R. M. (2001). Racial differences in youth employment. Monthly Lab. Rev., 124, 51.

9. Kneebone, E. (2014). The growth and spread of concentrated poverty, 2000 to 2008-2012. Brookings Institution Metropolitan Opportunity Series, (58). Retrieved from https://www.brookings.edu/interactives/the-growth-and-spreadof-concentrated-poverty-2000-to-2008-2012/

10. Erickson, D., Reid, C., Nelson, L., O’Shaughnessy, A., \& Berube, A. (Eds.). (2008). The Enduring Challenge of Concentrated Poverty in America: Case Studies from Communities across the U.S. The Federal Reserve System and the Brookings Institute. Retrieved from https://www.brookings.edu/wp-content/uploads/2016/06/1024_concentrated_poverty.pdf

11. Unites States Department of Agriculture. (2016, January). Rural America at A Glance: 2015 Edition. Retrieved from https://www.ers.usda.gov/publications/pub-details/?pubid=44016

12. Ayres, S. (2013, April). The high cost of youth unemployment. Washington: Center for American Progress. Retrieved from https://www.americanprogress.org/issues/economy/reports/2013/04/05/59428/the-high-cost-of-youth-unemployment/

13. U.S. Bureau of Labor Statistics. Labor Force Projections. Retrieved May 25, 2017 from https://www.bls.gov/emp/ep_ data_labor_force.htm

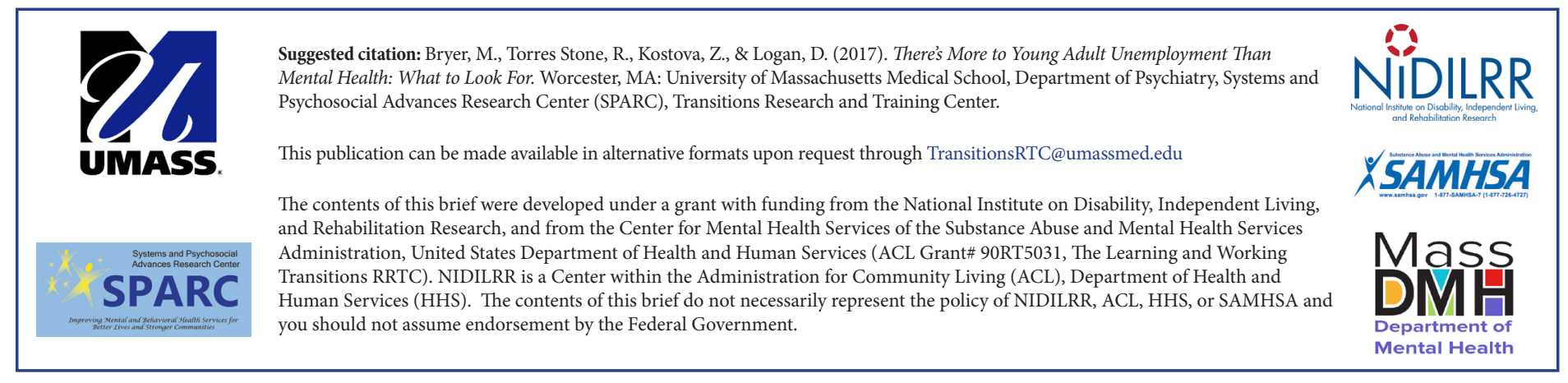

